\title{
SISTEM APLIKASI DESKTOP PENGOLAHAN DATA STOK BARANG PADA CV RIDHO FISHING
}

\author{
Tirta Ayu Retno Sari ${ }^{1}$, Didik Wiguna ${ }^{2}$, Sutrisno ${ }^{3}$ \\ Program Studi Teknik Informatika, Fakultas Teknik dan Ilmu Komputer, \\ Universitas Indraprasta PGRI \\ Jalan Raya Tengah No 80, Kelurahan Gedong, Pasar Rebo, Jakarta Timur \\ tirtaayu11@gmail.com¹, didik.wiguna@gmail.com², sutrisno3831@gmail.com ${ }^{3}$
}

\begin{abstract}
Abstrak
Sistem pengolahan data merupakan suatu sistem yang mengelola data-data penjualan pada suatu tempat. Permaslahan yang ada pada CV Ridho Fishing adalah belum adanya sistem aplikasi secara terkomputerisasi untuk mengelola stok barang sehingga masih menggunakan manual pencatatan. Program ini dibuat dengan menggunakan perangkat lunak XAMPP, dan NetBeans IDE 8.2 serta database MYSQL, program ini berfungsi untuk mengolah data stok barang pada CV Ridho Fishing, akhirnya peneliti dapat menarik kesimpulan bahwa dengan adanya sistem aplikasi ini, dapat membantu proses-proses yang ada di CV Ridho Fishing dengan mudah dan efisien sehingga dapat menghemat waktu.
\end{abstract}

Kata Kunci: sistem, aplikasi, desktop, pengolahan data, stok barang

\begin{abstract}
Data processing system is a system that manages sales data at a place. The problem in CV Ridho Fishing is the absence of a computerized application system for managing stock of goods so that it still uses manual recording. This program was created using XAMPP software, and NetBeans IDE 8.2 and MYSQL databases, this program serves to process stock data on CV Ridho Fishing, finally the researcher can draw the conclusion that with the existence of this application system, it can help the processes in CV Ridho Fishing is easy and efficient so you can save time.
\end{abstract}

Keywords: systems, applications, desktops, data processing, stock items

\section{PENDAHULUAN}

CV Ridho Fishing merupakan suatu usaha yang bergerak di bidang retail yang menjual berbagai macam pakan ternak dan alat pancing yang bertempat di kota depok. Untuk menunjang proses penjualan diperlukan aplikasi yang dapat memperlancar operasional perusahaan dengan pemanfaatan teknologi informasi sehingga segala kebutuhan informasi yang diperlukan perusahaan dapat terpenuhi. Sumber daya yang dimiliki oleh CV Ridho Fishing dirasa cukup mumpuni untuk melakukan operasional perusahann akan tetapi masih kurang efektif dan efesien dalam menangani masalah penjualan dan pengolahan data stok barang. Hal tersebut dikarenakan belum diterapkannya suatu aplikasi yang mendukung operasional khususnya dalam pengolaahan data stok barang yang dilakukan setiap hari. Akibatnya operasional dan laporan mengenai perkembangan perusahaan kurang begitu lancar dan optimal. Perancangan sistem administasi toko ini dibuat adalah untuk memudahkan pengelola stok barang setiap harinya serta memudahkan dalam proses transaksi jual beli dengan costumer agar kemajuan toko lebih terpantau secara akurat. Karena menggunakan buku dan kertas sebagai media pencatatan pengelolaan toko masih kurang efektif dan aman, sehingga di khawatirkan ada catatan yang hilang dan bisa mengganggu kearsipan dari toko tersebut, dan akan mempengaruhi dalam pemantauan perkembangan toko, sehingga di perlukan sebuah sistem pengolahan data yang terkomputerisasi untuk memudahkan kerja dari pengelola tokoPerolehan informasi juga akan lebih cepat di bandingkan dengan cara manual menggunakan buku, mudahmudahan rancangan aplikasi pengolahan data ini dapat terus dikembangkan dan bisa di gunakan pada toko-toko di Indonesia. 


\section{PENELITIAN RELEVAN}

Dalam rangka mendapatkan hasil penelitian yang baik, selain melakukan penelitian secara langsung peneliti juga melakukan kajian pustaka. Dari hasil yang telah dilakukan, beberapa hasil penelitian yang jadi acuan adalah:

Penelitian dari (Melki Fresli Gustom, 2018) yang berjudul "Sistem Aplikasi Penjualan Dan Stok Barang Di Nursery Agri Prospect" saat ini Permasalahan yang dialami Nursey Agri Prospect, yaitu tidak adanya sistem pengelolaan penjualan dan stok barang. Jumlah penjualan dan stok barang yang terus bertambah menuntut pihak karyawan untuk menghasilkan informasi yang cepat dan akurat. Sementara ini, pengelolaan penjualan dan stok barang masih dilakukan secara manual. Dengan adanya Sistem Aplikasi Penjualan dan Stok Barang ini diharapkan agar penginputan dan pengolahan data yang selama ini dikelola secara manual dapat segera mulai menggunakan sistem komputerisasi sehingga dapat meningkatkan kinerja karyawan dalam mengelola penjualan dan stok barang agar lebih efektif dan efisien. Penelitian dari (Agung Cahyo Wijoyo, 2020) yang berjudul "Analisis Sistem Perancangan Sistem Informasi Inventory pada PT Insan Data Permata" PT Insan Data Permata dalam kegiatan inventory masih dilakukan secara manual dan sering melakukan kesalahan, karena itu perlu adanya peningkatan sistem secara terkomputerisasi. Oleh karena itu, dirancang suatu sistem informasi administrasi pembayaran, perangkat lunak yang dibangun menggunakan Netbeans dan MySQL sebagai databasenya. Dengan dibuatnya sistem informasi administrasi pembayaran ini dapat memudahkan dan memaksimalkan pekerjaan bendahara dalam mengolah informasi, ketelitian maupun pelayanan secara efektif dan efisien.

\section{METODE PENELITIAN}

Kesulitan dalam mencatat dan menghitung banyaknya jenis barang, jumlah barang, maupun besarnya jumlah harga, mengakibatkan data yang diperoleh menjadi kurang akurat. Untuk meningkatkan keakuratan data, diperlukan pembangunan sistem informasi penjualan barang yang terkomputerisasi (Fendi Nurcahyono, 2012).

Metode pengumpulan data yang dilakukan oleh peneliti untuk mendapatkan data-data serta informasi untuk mendukung penyempurnaan hasil dari penelitian ini antara lain:

1. Observasi

Pengamatan secara langsung terhadap objek penelitian dengan memperhatikan fakta-fakta yang berkaitan dengan objek penelitian observasi dilakukan untuk mengetahui situasi dan kondisi sebelum dilakukan penelitian.

2. Studi Pustaka

Yakni metode pengumpulan data dengan cara mempelajari beberapa buku, internet, sarana perpustakaan, dan catatan-catatan kuliah yang berhubungan dengan yang diajukan.

3. Wawancara

Melalui teknik ini dimana diadakan wawancara kepada Bapak Supriyno selaku Owner CV Ridho Fishing untuk mengetahui hal-hal yang terkait pada semua data yang terkait, dan proses sistem informasi management project. Selain itu, wawancara juga dilakukan kepada beberapa pegawai/staff yang ada.

\section{HASIL DAN PEMBAHASAN}

\section{Use Case Diagram}

Use case diagram yaitu salah satu jenis diagram pada UML yang menggambarkan interaksi antara sistem dan aktor, use case diagram juga dapat men-deskripsikan tipe interaksi antara si pemakai sistem dengan sistemnya(Rouse, 2015). 


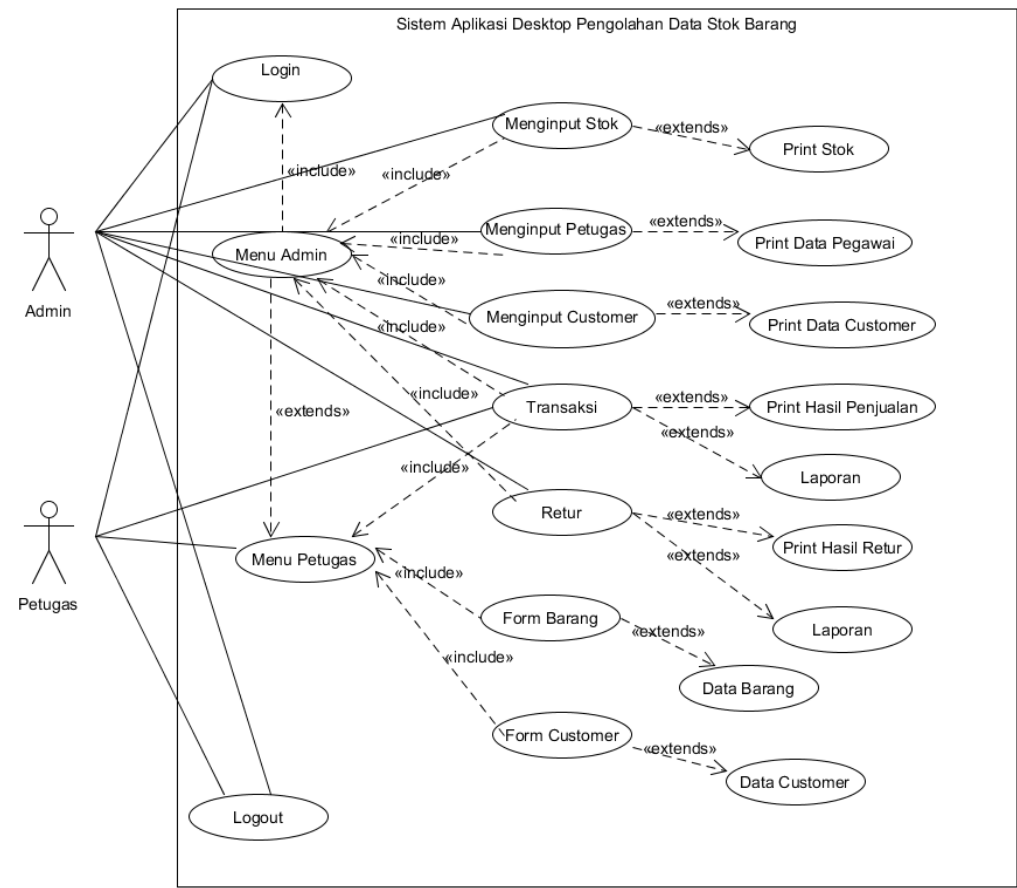

Gambar 1. UML (Unified Modelling Language)

\section{Activity Diagram}

Activity Diagram merupakan rancangan aliran aktivitas atau aliran kerja dalam sebuah sistem yang akan dijalankan (Mulyani, 2017).

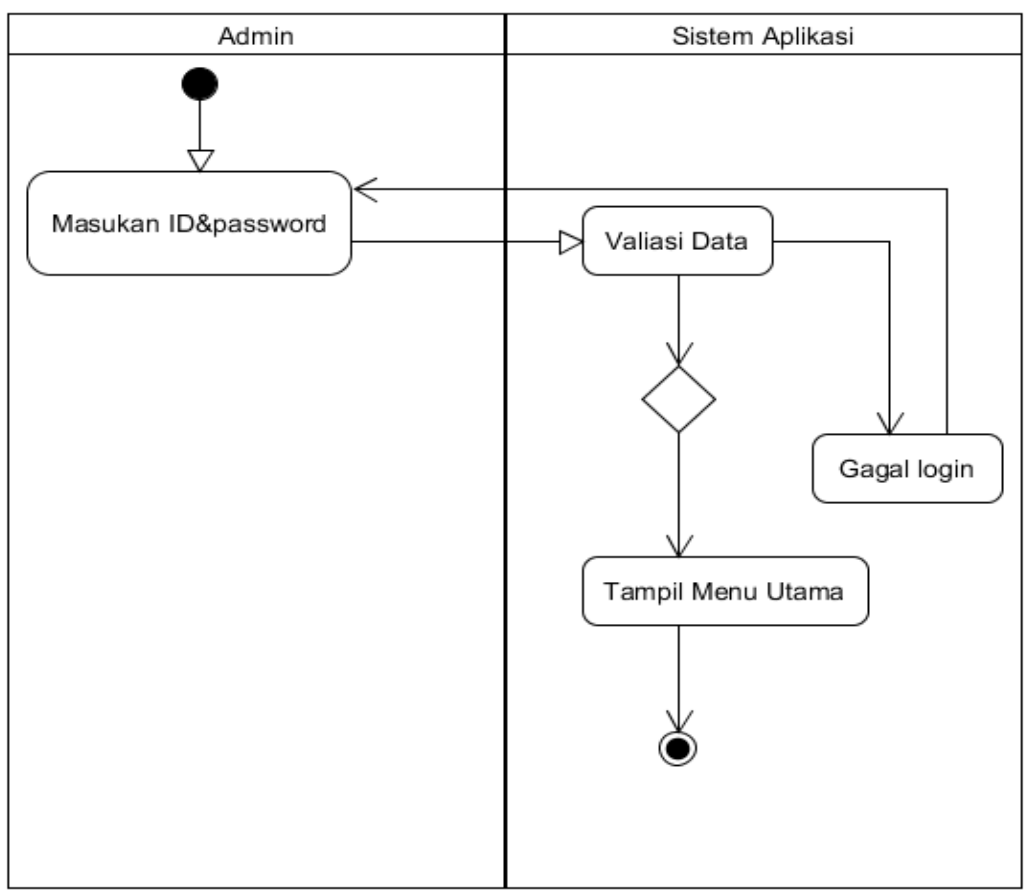

Gambar 2. Activity Diagram Login 


\section{Class Diagram}

Diagram class dapat dikatakan bersifat statis, alasannya karena diagram kelas tidak menggambarkan apa yang terjadi jika mereka berhubungan melainkan menggambar hubungan apa yang terjadi (Rosa AS, 2014).

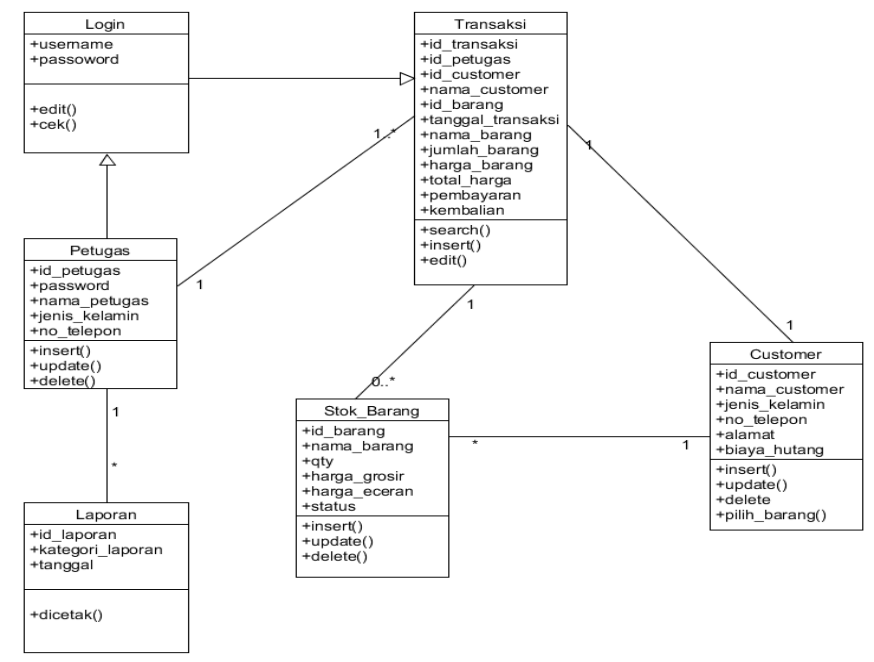

Gambar 3. Class Diagram

\section{Sequence Diagram}

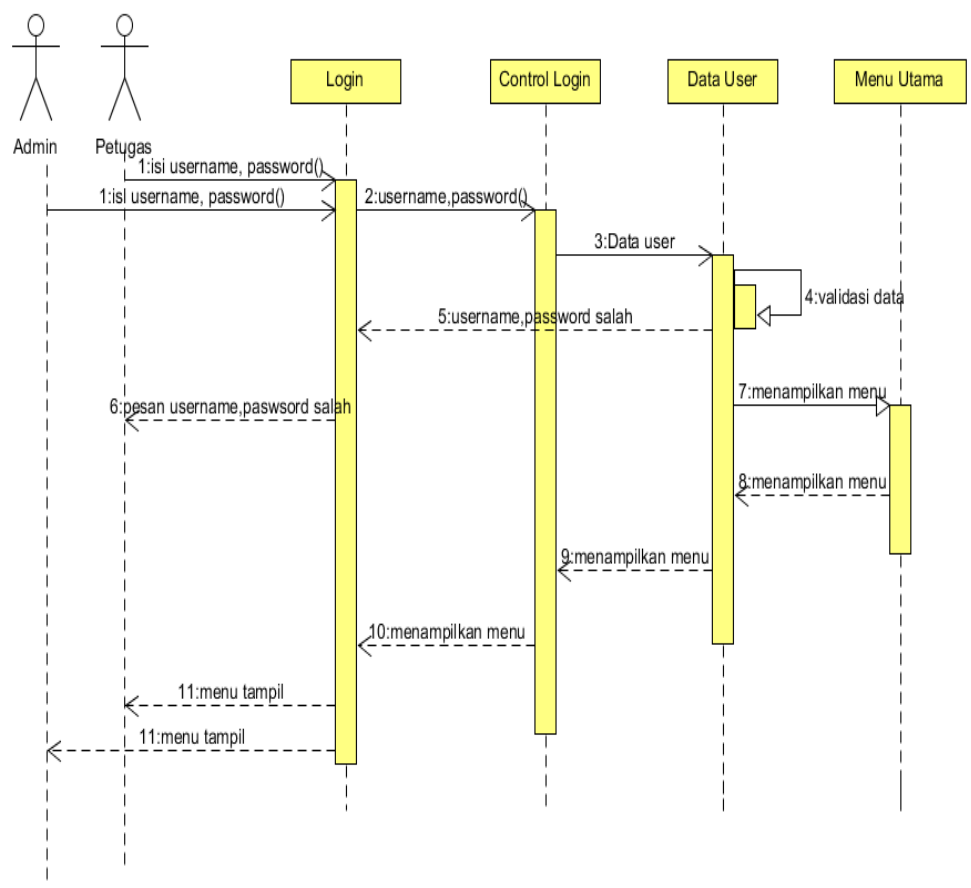

Gambar 4. Sequence Diagram 


\section{Tampilan Layar}

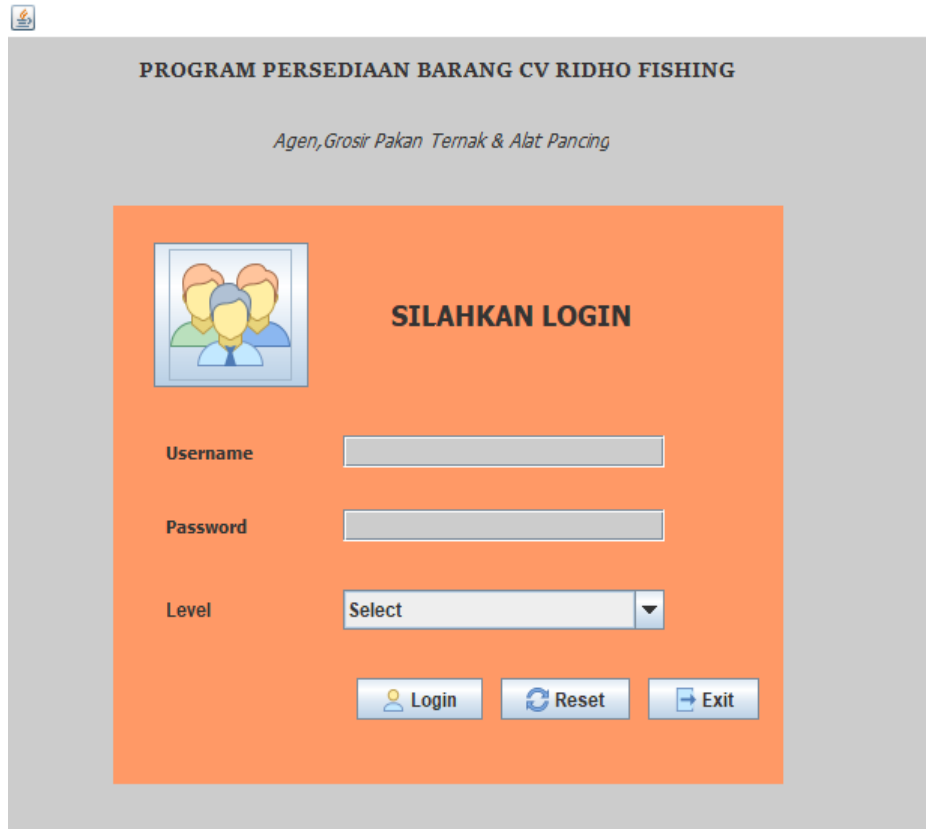

Gambar 5. Tampilan Layar Login

Form masukan login ini muncul di saat awal pengoperasian program dan akan menjadikan login multiuser yang nanti akan menampilkan form menu admin dan form menu petugas.

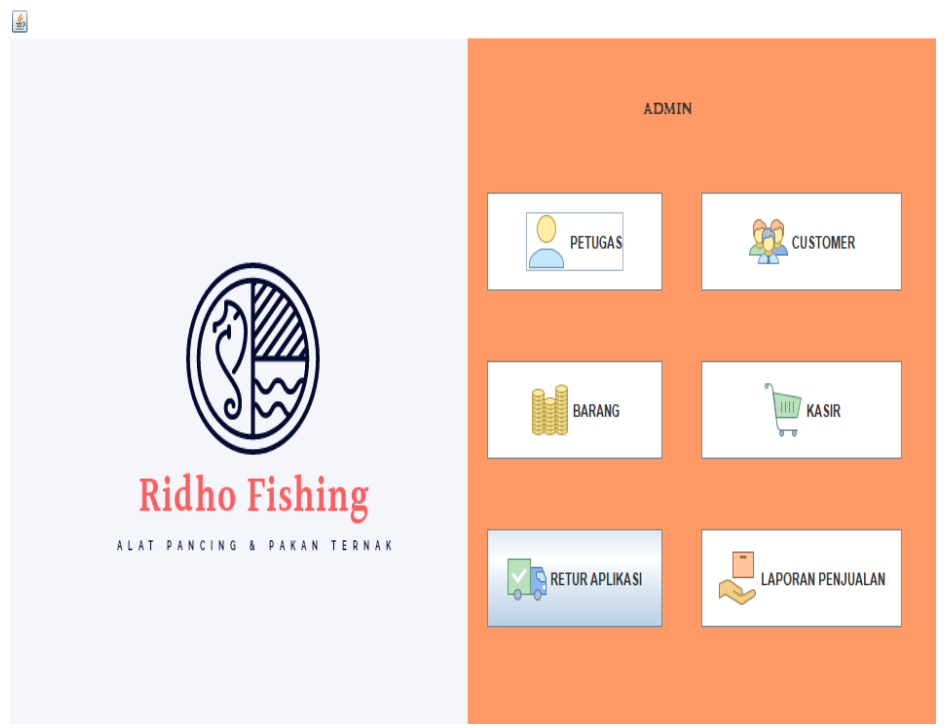

Gambar 6. Tampilan Layar Menu Admin

Form menu admin akan menampilkan form-form yang hanya bisa di akses oleh admin. 


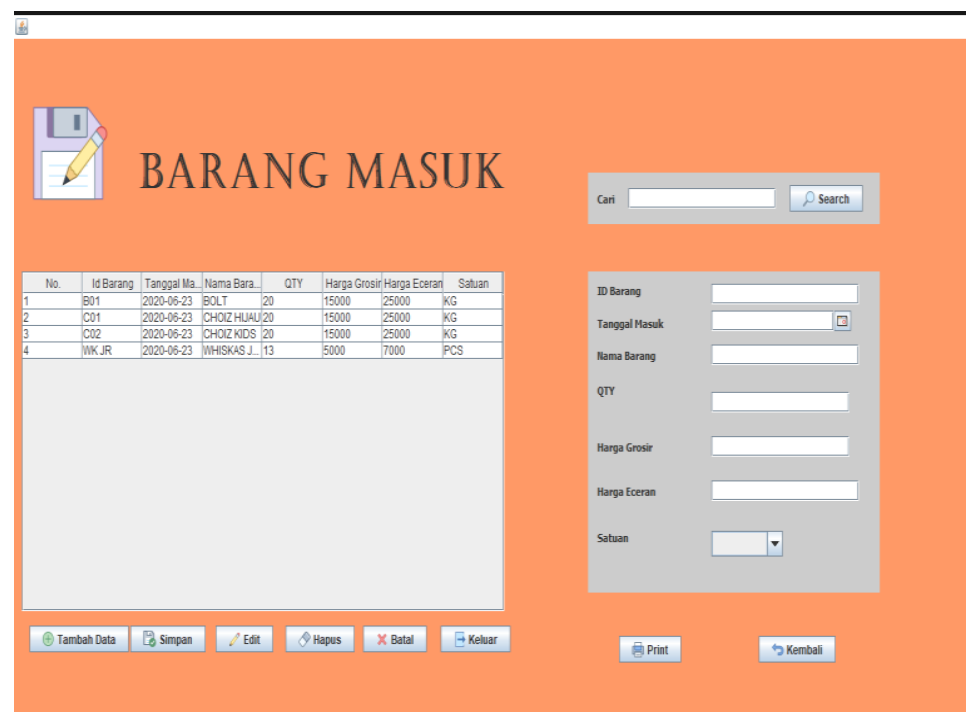

Gambar 7. Tampilan Layar Barang Masuk

Form barang masuk ini mempunyai fungsi CRUD dan mencari data yang ingin di cari dan hanya bisa di akses oleh admin.

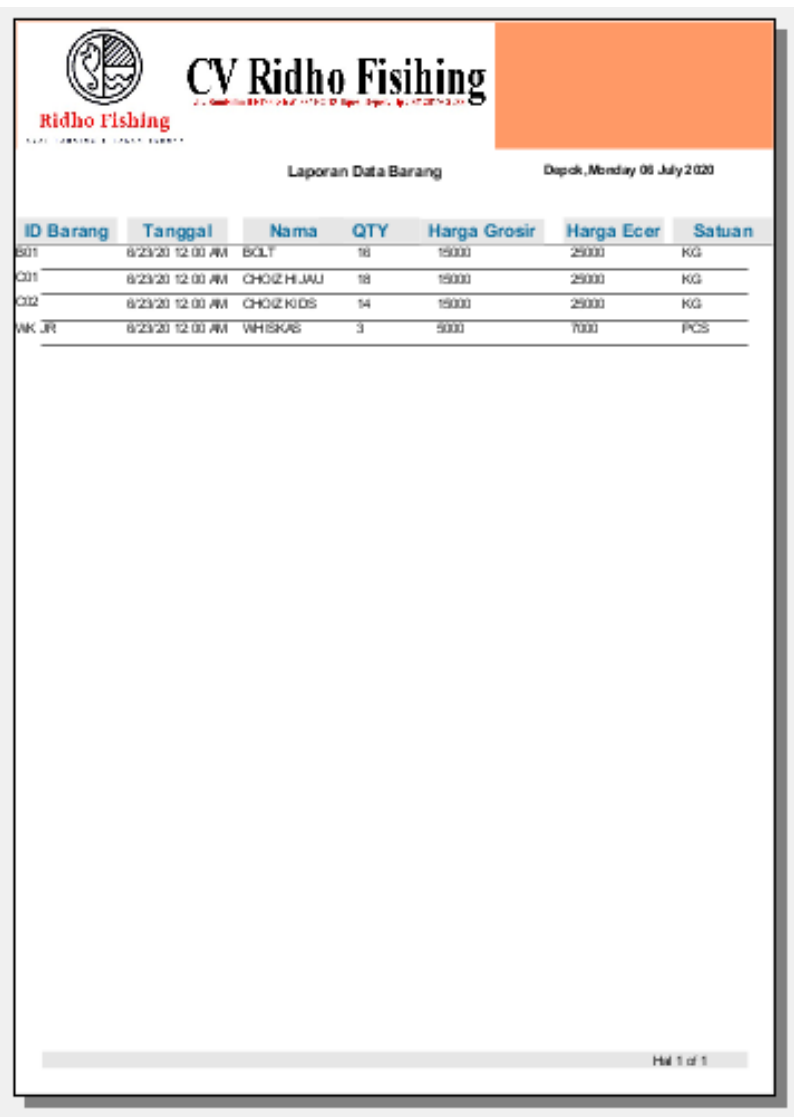

Gambar 8. Tampilan Layar Report Barang 


\section{SIMPULAN}

Dengan adanya sistem aplikasi pengolahan data stok barang ini dapat membantu kinerja keuangan dan wakru terutama dalam melakukan pengelolaan stok barang dan laporan penjualan ini juga memudahkan proses pembuatan laporan. Sistem aplikasi pengolahan data stok barang ini dirancang dengan tujuan memudahkan staff dalam mengelola stok barang, mengambil keputusan dan mendapat laporan.

\section{DAFTAR PUSTAKA}

Abdurahman, M. (2017). SISTEM INFORMASI PENGOLAHAN DATA PEMBELIAN DAN PENJUALAN PADA TOKO KOLONCUCU TERNATE. IJIS - Indonesian Journal On Information System. https://doi.org/10.36549/ijis.v2i1.22

Fendi Nurcahyono. (2012). Pembangunan Aplikasi Penjualan Dan Stok Barang Pada Toko Nuansa Elektronik Pacitan. Sentra Penelitian Engineering Dan Edukasi.

Markito, L., Sumirat, E. W., \& Sukadi. (2013). Pembangunan Sistem Informasi Penjualan pada Toko Harapan Sentosa Elektronik Kecamatan Kebonagung Kabupaten Pacitan. IJNS - Indonesian Journal on Networking and Security.

Mulyani, S. (2017). Pengertian Activity Diagram. In Analisis dan Perancangan Sistem Informasi Manajemen Keuangan Daerah: Notasi Pemodelan Unified Modeling Language (UML).

Nawang, M., Kurniawati, L., \& Duta, D. (2017). Rancang Bangun Sistem Informasi Pengolahan Data Persediaan Barang Berbasis Dekstop Dengan Modelwaterfall. Jurnal PILARNusa Mandiri.

Ramdhany, T., \& Kurnia, D. (2016). PERANCANGAN SISTEM INFORMASI PERSEDIAAN BARANG DAGANG DI PT DIMARCO MITRA UTAMA CABANG BANDUNG. Jurnal Rekayasa Sistem \& Industri (JRSI). https://doi.org/10.25124/jrsi.v3i01.37

Rosa AS, m. S. (2014). Pengertian Class Diagram. Rekayasa Perangkat Lunak.

Rouse, M. (2015). use case diagram ( UML use case diagram ). Rekayasa Perangkat Luna.

Sawitri, D. (2010). Perancangan sistem informasi manajemen persediaan barang "electrolux authorized service cv. momentum teknik." Universitas Gunadarm.

Wibowo, R. A. (2009). Sistem Informasi Persediaan Keluar Masuk Barang Pada Inside Distro Jakarta. Spead. 